Trauma Surgery \& Acute Care Open

\title{
Shotgun wound to manubrium sterni, right anterior neck, and right supraclavicular area
}

\author{
David V Feliciano
}

Surgery, University of Maryland School of Medicine, Baltimore, Maryland, USA

Correspondence to Dr David V Feliciano; davidfelicianomd@gmail.com

\section{HISTORY}

A 38-year-old man presented to the trauma center with a close-range oblique shotgun wound to the manubrium sterni, right anterior neck, and right supraclavicular area.

\section{EXAMINATION}

The patient was alert and responsive on arrival. His initial vital signs included a heart rate of 110 beats per minute, a systolic blood pressure of 100 $\mathrm{mm} \mathrm{Hg}$, and a respiratory rate of 20 per minute. There was a $12 \mathrm{~cm}$ wide by $4 \mathrm{~cm}$ high rectangular avulsion of the skin extending from the medial left infraclavicular area across the manubrium sterni and the lower anterior neck. At the right end of the defect was a deep hole $3 \mathrm{~cm}$ in diameter which had been stuffed with dry mesh gauze by an emergency medical technician at the scene prior to transport to the trauma center. Unfortunately, the gauze was saturated with arterial blood.

\section{QUESTION}

The most appropriate first step in the management of this patient in addition to resuscitation is:

A. Transfemoral insertion of a resuscitative endovascular balloon occlusion of the aorta device.

B. Bilateral anterolateral thoracotomy at the third interspace.

C. Endotracheal intubation.

D. Cricothyroidotomy.

\section{MANAGEMENT}

There was no clear-cut air leak from the deep anterior cervical hole. Therefore, endotracheal intubation was performed in the emergency room, followed by an anterior X-ray of the neck and upper chest (figure 1). Manual compression was applied to the blood-soaked gauze in the wound in the lower anterior neck as the patient was moved to the operating room.

The patient's upper extremities were placed at his sides, and a transverse shoulder roll was used to hyperextend the neck. Findings on physical examination (left-to-right oblique shotgun wound with deep hole in the suprasternal area) and X-ray (pellets concentrated in the medial right supraclavicular area) were reviewed prior to deciding on the most appropriate incision. permitted under CC BY-NC. No commercial re-use. See rights and permissions. Published by BMJ.

To cite: Feliciano DV. Trauma Surg Acute Care Open

2020;5:e000454.

\section{QUESTION}

The most appropriate incision in this patient would vary from surgeon to surgeon, but which one of the following would you choose?

A. High transverse cervical incision.
B. Median sternotomy.

C. Right supraclavicular incision.

D. Right oblique cervical incision.

\section{MANAGEMENT}

Based on the oblique track of the pellets, midline hemorrhage, and location of the pellets thought to be superior to the right subclavian vessels, a right oblique cervical incision was made along the anterior edge of the right sternocleidomastoid muscle. As compression was applied to the midline wound, the right common carotid artery was encircled with a vessel loop just superior to the right sternoclavicular joint. As the artery was elevated, arterial hemorrhage was noted approximately $2 \mathrm{~cm}$ inferior to the vessel loop in the right superior mediastinum. A 50\% wall defect in the proximal right common carotid artery was visualized and quickly covered with the surgeon's right index finger (figure 2). For proximal control, a medium-sized Satinsky clamp was then placed at the origin of the right common carotid artery from the innominate artery. For distal control, an angled DeBakey clamp was placed on the proximal right common carotid artery approximately $2 \mathrm{~cm}$ above the area of injury. The artery was transected at the area of injury, both ends were sharply debrided, and an end-to-end anastomosis was performed with two continuous 5-0 polypropylene sutures $\left(180^{\circ}\right.$ each) (figure 3$)$. Both ends of the anastomosis were flushed before the last knot was tied down, and flow was then restored to the right neck, scalp, and brain. Arterial clamp time was approximately 25 minutes. As several perforations of the anterior trachea were present and the anterior defect in the cervical soft tissue was so large, the perforations were repaired and a tracheostomy was performed.

The patient was neurologically intact when he awakened. Daily wet-to-dry dressing changes were performed on the anterior defect in the cervical soft tissue around the tracheostomy, which was removed 10 days later (figure 4). The cervical wound gradually filled in as a wide scar over 4 weeks.

\section{DISCUSSION}

External arterial hemorrhage from a cervical or supraclavicular wound is uncommon. Options for temporary vascular control include widening the entrance site on the skin and inserting a finger, gauze packing, or a Foley balloon catheter. ${ }^{12}$

In the patient described, control of arterial hemorrhage from the right common carotid artery with packing was incomplete. Also, there was a concern about other pellet injuries in the lower 


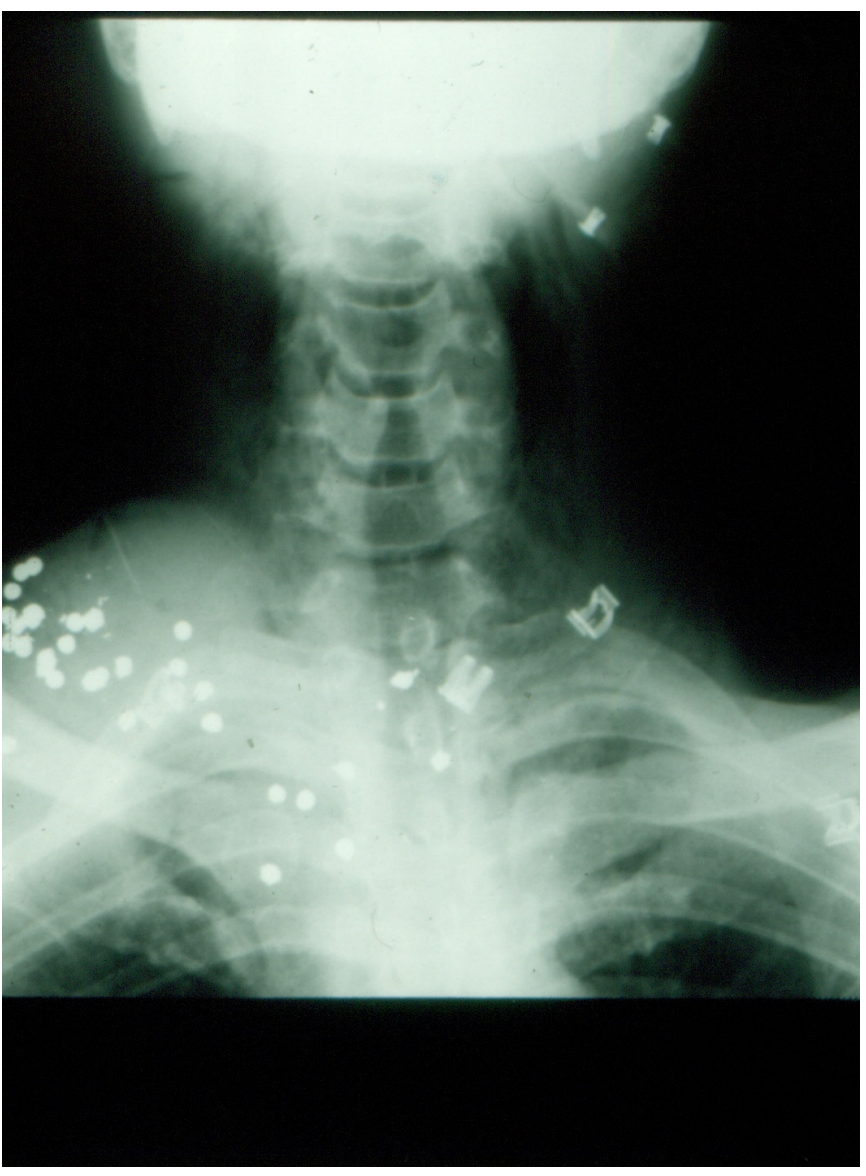

Figure 1 An X-ray of the lower neck and upper chest demonstrating the distribution of the shotgun pellets.

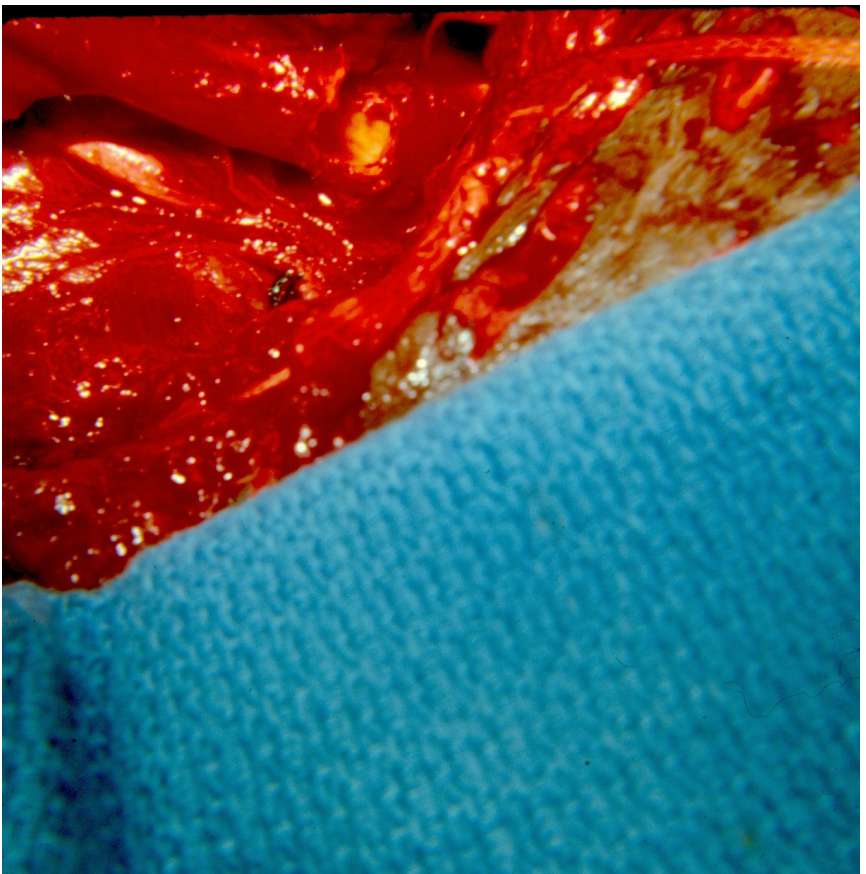

Figure 2 Perforation of the proximal right common carotid artery just above the bifurcation of the innominate artery.

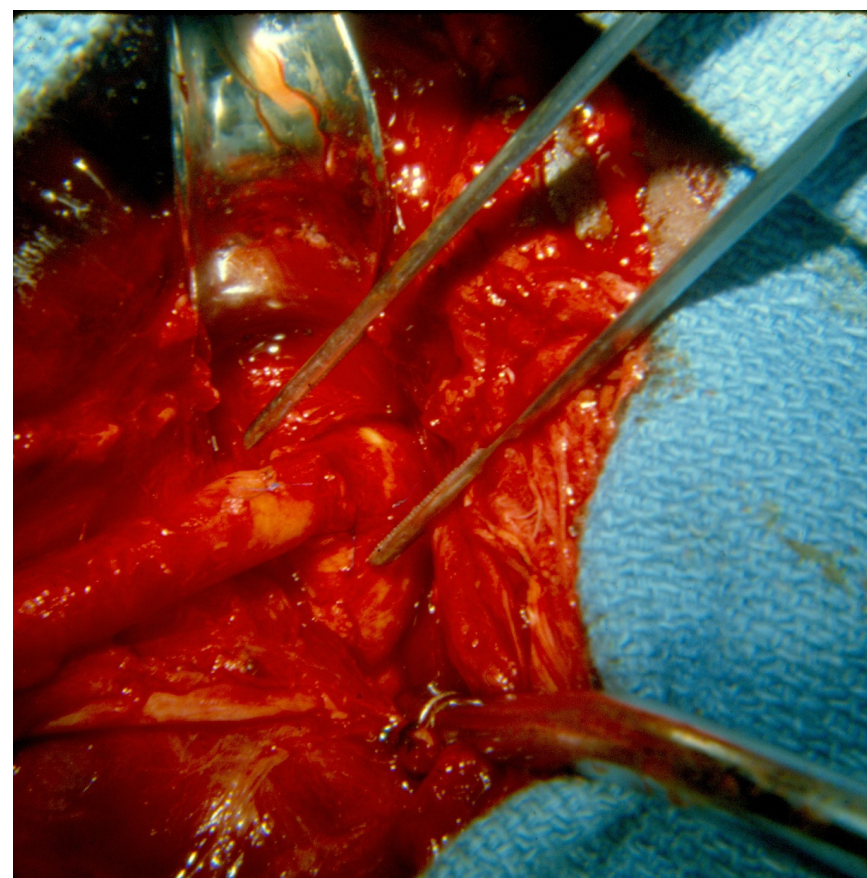

Figure 3 End-to-end anastomosis of the proximal right common carotid artery. The right subclavian artery is seen inferior to the anastomosis.

neck (low zone II in the original article on zones of the neck by Monson $\mathrm{et}^{\mathrm{a}} \mathrm{l}^{3}$ ). This precluded the use of an endovascular stent graft for repair. ${ }^{45}$ As noted above, the choice of incision in this patient turned out to be correct. It allowed for visualization and repair of an arterial wound in the right superior mediastinum without the need for a thoracic incision.

As a general rule, the choice of incision with penetrating wounds of the superior mediastinum and/or lower neck when the patient has active arterial hemorrhage depends on the following: (1) hemodynamic status; (2) whether packing or a balloon catheter has controlled the hemorrhage from the wound; (3) location of entrance and/or exit wounds; and (4) whether a chest X-ray can be performed if a shotgun wound has occurred (distribution of pellets). In the patient with a superior mediastinal wound and systolic blood pressure $>90 \mathrm{~mm} \mathrm{Hg}$ (arbitrary choice), a median sternotomy allows for optimal exposure of the heart and great vessels except for the left subclavian artery. This incision can then be extended to an oblique cervical or supraclavicular

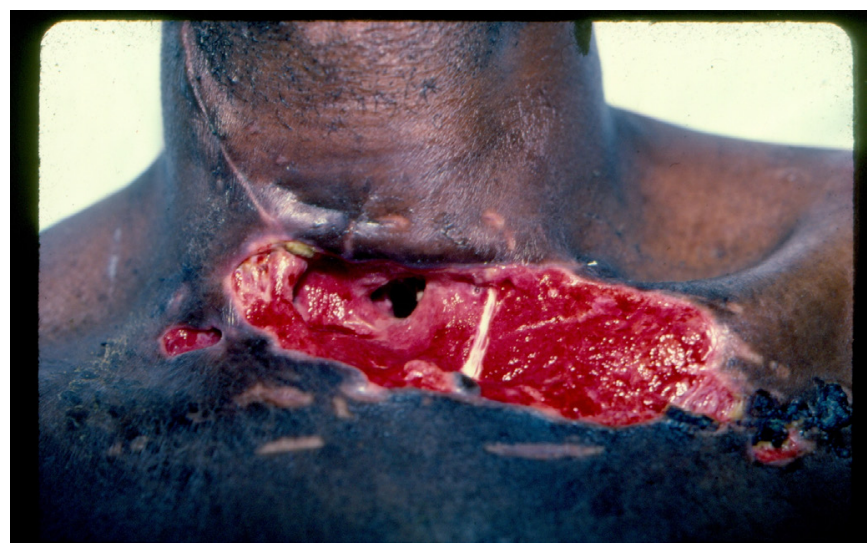

Figure 4 The patient's postoperative wound after removal of the tracheostomy tube. 
incision if distal vascular control of an injured common carotid or subclavian artery is needed, respectively. In the patient with profound hypotension, a bilateral anterolateral thoracotomy is performed. The interspace chosen on the side of injury should be above the nipple if there is intrapleural hemorrhage suspected to be from the extrapleural subclavian artery and/or vein. When the "wrong" incision has been chosen, the "right" incision should be added as the extensive blood supply of the chest wall and neck will almost always allow for postoperative healing.

The options for repair of the common carotid artery with 5-0 or 6-0 polypropylene suture are as follows: (1) lateral arteriorrhapy; (2) patch arterioplasty with thin-walled polytetrafluoroethylene (PTFE) or bovine pericardium; (3) resection with end-to-end anastomosis; (4) resection with insertion of a saphenous vein graft (did you prepare and drape the thigh?) or PTFE prosthesis; or on the rarest of occasions, (5) transposition of the mobilized external carotid artery to replace the junction of the common carotid and internal carotid arteries. Ligation is only performed when there is exsanguinating hemorrhage at the base of the skull and an external or transcarotid balloon cannot be passed to control hemorrhage.

Systemic heparinization (100 units $/ \mathrm{kg}$ ) is appropriate when the cross-clamp time is likely to be prolonged $>30$ minutes (resection with end-to-end anastomosis, insertion of an interposition graft, or injury near the base of the skull in high zone II or zone III). In the patient with a shotgun wound and significant injuries to the soft tissue or other associated injuries, "regional" heparinization (50 units of unfractionated heparin with $20-25 \mathrm{~mL}$ injected proximally and distally $=2000-2500$ units) is a better choice.

Temporary intraluminal vascular shunts are not indicated routinely in wounds to the innominate, common carotid, or internal carotid arteries. This is particularly true if the patient's hypotension from hemorrhage can be rapidly reversed with the transfusion of blood, and the repair can be completed in the previously mentioned 30 minutes. The exception would be an injury in the aforementioned high zone II or zone III of the neck. ${ }^{6}$ At these locations, control of hemorrhage from the common or internal carotid artery can be obtained by direct surgical exposure or by percutaneous (brachial or radial artery) or transcarotid passage of a balloon catheter as previously noted. Carotid occlusive time, however, becomes a factor with all of these approaches. Surgical exposure may require the time needed to complete one of the following two approaches: (1) subluxation of the temporomandibular joint with interdental wiring; or (2) a vertical ramus mandibulotomy performed by the oral surgery service. ${ }^{7}$ Should an endovascular stent graft be chosen rather than an open direct repair after balloon control of hemorrhage, the time factor is still an issue.

A major concern in this patient was the presence of an arterial suture line in proximity to an open wound in the anterior neck (shotgun wound $\rightarrow$ tracheostomy $\rightarrow$ open wound). The usual buttress of the detached sternal head only or the entire inferior sternocleidomastoid muscle would not have reached the arterial suture line in the superior mediastinum. ${ }^{9}{ }^{10}$ Fortunately, there was enough mediastinal soft tissue to surround the arterial suture line during the period when there was still a hole in the lower anterior neck.

Funding The authors have not declared a specific grant for this research from any funding agency in the public, commercial or not-for-profit sectors.

Competing interests None declared.

Patient consent for publication Not required.

Provenance and peer review Commissioned; internally peer reviewed.

Open access This is an open access article distributed in accordance with the Creative Commons Attribution Non Commercial (CC BY-NC 4.0) license, which permits others to distribute, remix, adapt, build upon this work non-commercially, and license their derivative works on different terms, provided the original work is properly cited, appropriate credit is given, any changes made indicated, and the use is non-commercial. See: http://creativecommons.org/licenses/by-nc/4.0/.

\section{REFERENCES}

1. Navsaria P, Thoma M, Nicol A. Foley catheter balloon tamponade for life-threatening hemorrhage in penetrating neck trauma. World J Surg 2006;30:1265-8

2. Ball CG, Wyrzykowski AD, Nicholas JM, Rozycki GS, Feliciano DV. A decade's experience with balloon catheter tamponade for the emergency control of hemorrhage. J Trauma 2011;70:330-3.

3. Monson DO, Saletta JD, Freeark RJ. Carotid vertebral trauma. J Trauma 1969;9:987-99.

4. Reuben BC, Whitten MG, Sarfati M, Kraiss LW. Increasing use of endovascular therapy in acute arterial injuries: analysis of the National trauma data bank. J Vasc Surg 2007:46:1222-6.

5. Branco BC, DuBose JJ, Zhan LX, Hughes JD, Goshima KR, Rhee P, Mills JL. Trends and outcomes of endovascular therapy in the management of civilian vascular injuries. J Vasc Surg 2014;60:1297-307.

6. Feliciano DV, Subramanian A. Temporary vascular shunts. Eur J Trauma Emerg Surg 2013;39:553-60.

7. Fisher DF, Clagett GP, Parker JI, Fry RE, Poor MR, Finn RA, Brink BE, Fry WJ. Mandibular subluxation for high carotid exposure. J Vasc Surg 1984;1:727-33.

8. Larsen PE, Smead WL. Vertical ramus osteotomy for improved exposure of the dista internal carotid artery: a new technique. J Vasc Surg 1992;15:226-31.

9. Harfouche M, Scalea TM, Feliciano DV. Complex penetrating cervical wound. Trauma Surg Acute Care Open 2019:4:e000354

10. Feliciano DV. Management of penetrating injuries to carotid artery. World J Surg 2001:25:1028-35. 